\section{A) Check for updates}

Cite this: Inorg. Chem. Front., 2020, 7, 3909

Received 16th July 2020,

Accepted 3rd September 2020

DOI: 10.1039/d0qi00854k

rsc.li/frontiers-inorganic

\title{
Magnetic exchange interactions in symmetric lanthanide dimetallics $\uparrow$
}

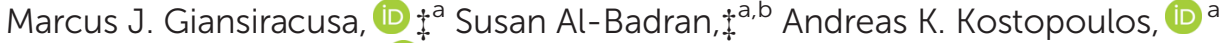 \\ George F. S. Whitehead, (D) a Eric J. L. Mclnnes, ${ }^{a}$ David Collison, ${ }^{\text {a }}$ \\ Richard E. P. Winpenny (D) ${ }^{a}$ and Nicholas F. Chilton (D)*a
}

\begin{abstract}
We report the synthesis and characterization of two symmetric homo-dimetallic lanthanide complexes based on methyl-substituted 8-hydroxyquinoline ( $\mathrm{HMeQ}$ ). The aryloxo-bridged core gives rise to weak magnetic coupling between pairs of $\mathrm{Er}^{\mathrm{III}}$ and $\mathrm{Yb}^{\mathrm{III}}$ ions, as revealed by magnetic and EPR spectroscopy studies. EPR measurements of magnetically dilute species, coupled with CASSCF-SO calculations, allows modelling of the EPR spectra of the exchange coupled species and the magnetic data simultaneously. This work adds to the database of exchange coupled $\{L n\}_{2}$ molecules which have been thoroughly characterised by EPR spectroscopy and modelled using an $S_{\text {eff }}=1 / 2$ approach to describe the interaction of ground Kramers states, and highlights the differences between centro-symmetric and asymmetric dimetallics.
\end{abstract}

\section{Introduction}

The unique chemistry of the trivalent lanthanides $\left(\operatorname{Ln}^{\mathrm{III}}\right)$ stems from their electronic configuration with the $4 \mathrm{f}$ orbitals shielded by filled $5 s^{2} 5 p^{6}$ subshells. ${ }^{1}$ This makes $\mathrm{Ln}^{\mathrm{III}}$ ions extremely stable, hard Lewis acids with a tendency towards high coordination numbers. ${ }^{2}$ The optical and magnetic properties of lanthanide complexes have attracted much attention over the past two decades, ${ }^{3-7}$ for applications in medical imaging, molecular magnetism and quantum information processing (QIP). ${ }^{5-10}$ Dimetallic Ln $^{\mathrm{III}}$ complexes, where the ions are close enough to allow a magnetic interaction, can open new avenues for QIP, ${ }^{4,11-14}$ and also provide a simple model to study the fundamental magnetic interactions between 4 f electronic manifolds. ${ }^{15}$

The 8-hydroxyquinoline pro-ligand and its derivatives are employed primarily in gravimetric analysis and as extraction reagents due to their excellent chelating properties that are applicable to many metals including lanthanides. ${ }^{16,17}$ Furthermore, they have attracted interest in use for preparing coordination complexes since the report of tris-8-oxoquinolinato aluminium in $1987,{ }^{18,19}$ and more recently for generating polymetallic lanthanide complexes. ${ }^{20-26}$ We have recently used

\footnotetext{
${ }^{a}$ Department of Chemistry, The University of Manchester, Oxford Road, Manchester, M13 9PL, UK. E-mail: david.collison@manchester.ac.uk,

nicholas.chilton@manchester.ac.uk

${ }^{b}$ Chemistry Department, College of Science, Basrah University, Basrah, Iraq

$\dagger$ Electronic supplementary information (ESI) available: Characterisation, EPR, CASSCF and SQUID data. CCDC 2015503-2015505. For ESI and crystallographic data in CIF or other electronic format see DOI: 10.1039/d0qi00854k

\$These two authors contributed equally.
}

this pro-ligand to assemble a series of asymmetric lanthanide dimetallics to study the magnetic interactions by magnetometry, electron paramagnetic resonance (EPR) and inelastic neutron scattering (INS) spectroscopies. ${ }^{27,28}$ We found that the exchange interactions for the asymmetric $\mathrm{Dy}_{2}$ and $\mathrm{Er}_{2}$ species are reasonably well described by the point-dipole model, however, there is a non-negligible superexchange component. ${ }^{27,28}$ For the $\mathrm{Yb}_{2}$ asymmetric species, the pointdipole calculation underestimates the interaction, which is clearly dominated by superexchange. ${ }^{27}$

Here, we study a related series of centro-symmetric molecular dimetallics ( $C_{i}$ point group symmetry), prepared using 2-methyl-8-hydroxyquinoline (HMeQ) with formula $\left[\operatorname{Ln}_{2}\left(\mathrm{HMeQ}^{*}\right)_{4}\left(\mathrm{NO}_{3}\right)_{6}\right]$ where $\operatorname{Ln}^{\mathrm{III}}=\operatorname{Er}^{\mathrm{III}}(\mathbf{1}), \mathrm{Yb}^{\mathrm{III}}(2)$ and $\mathrm{Y}^{\mathrm{III}}$ (3), in which the pro-ligand is deprotonated at $\mathrm{O}$ and protonated at $\mathrm{N}$. The structures of the $\mathrm{Y}^{\mathrm{III}}, \mathrm{La}^{\mathrm{III}}, \mathrm{Gd}^{\mathrm{III}}$, Dy ${ }^{\mathrm{III}}$ and $\mathrm{Yb}^{\mathrm{III}}$ analogues have been reported previously, ${ }^{29,30}$ and here we report the novel $\mathrm{Er}^{\mathrm{III}}$ analogue. Herein, we study 1 and 2 with multi-frequency EPR spectroscopy, following our previous work, ${ }^{27,28}$ in order to add to the database of exchange coupled species that have been comprehensively studied experimentally. We employ a pseudospin $S=1 / 2$ approach to fit the EPR spectra to extract the nature of the low-lying exchange coupled states to allow benchmarking of theoretical models. ${ }^{31}$

\section{Results}

\section{Synthesis}

A family of three lanthanide complexes with the formula $\left[\mathrm{Ln}_{2}\left(\mathrm{HMeQ}^{*}\right)_{2}\left(\mathrm{NO}_{3}\right)_{6}\right]\left(\mathrm{HMeQ}^{*}\right.$ is the zwitterion deprotonated 
at $\mathrm{O}$ and protonated at $\mathrm{N} ; \mathrm{Ln}=\mathrm{Er}(1), \mathrm{Yb}(2)$ and $\mathrm{Y}(3))$ were synthesised by reacting hydrated lanthanide nitrate Ln $\left(\mathrm{NO}_{3}\right)_{3} \cdot x \mathrm{H}_{2} \mathrm{O}$ and HMeQ in a molar ratio of $1: 2$ in methanol. After heating to reflux for 3 hours, the solution was filtered and slowly evaporated yielding yellow block-shape crystals suitable for single crystal X-ray diffraction, which revealed the symmetric Ln $^{\text {III }}$ dimetallics. The doped samples (Ln@3), where Ln $=\operatorname{Er}(\mathbf{1 a})$ or $\mathrm{Yb}(\mathbf{2 a})$, were synthesised using the same procedure but employing a mixture of $\mathrm{Ln}\left(\mathrm{NO}_{3}\right)_{3} \cdot x \mathrm{H}_{2} \mathrm{O}$ and $\mathrm{Y}\left(\mathrm{NO}_{3}\right)_{3} \cdot x \mathrm{H}_{2} \mathrm{O}$ in a $1: 19$ molar ratio with HMeQ in methanol $(1: 49$ ratio for the 2a EPR spectroscopy sample).

\section{Structural description}

The complexes $\left[\mathrm{Ln}_{2}\left(\mathrm{HMeQ}^{*}\right)_{2}\left(\mathrm{NO}_{3}\right)_{6}\right]$ 1-3 crystallise in the monoclinic space group $P 2_{1 / n}$, Fig. $1, \mathrm{~S} 1$, and Table S1/2. $\dagger$ The structure lies about a crystallographic inversion centre. Here, the structure of $\mathbf{1}$ is described as representative of the isostructural series.

The $\mathrm{Er}^{\mathrm{III}}$ site is bonded to three chelating nitrate anions, two $\mu$-O-atoms from bridging $\mathrm{HMeQ}^{*}$ ligands and an $\mathrm{O}$-atom from a third terminal $\mathrm{HMeQ}^{*}$ unit. The Er-Er distance is 3.8725(7) $\AA$ and the Er-O-Er angle is $112.3(2)^{\circ}$, compared to the shorter 3.4456(8) $\AA$ distance between the two $\mathrm{Er}^{\mathrm{III}}$ ions in the asymmetric dimetallic $\left[\mathrm{H}_{2} \mathrm{Q}\right]\left[\mathrm{Ln}_{2}(\mathrm{Q})_{4}\left(\mathrm{NO}_{3}\right)_{3}\right] \cdot \mathrm{MeOH}$, which contains an unsubstituted oxoquinolinate (HQ) molecule. ${ }^{28}$ The smaller separation in the asymmetric molecule is likely a result of the reduced steric bulk which allowed three bridging ligands forcing a wider Er-O-Er angle 96.6(7) ${ }^{\circ}$.

The coordination of the $\mathrm{Er}^{\mathrm{III}}$ site consists of nine oxygen atoms: the shortest Er-O distance, 2.189(8) $\AA$, is to the oxygen from the terminal $\mathrm{HMeQ}^{*}$. The two bonds to the $\mu-\mathrm{O}$ from HMeQ $^{*}$ have 2.328(7) and 2.334(5) A distances. The six oxygen atoms from three chelating nitrate ligands have longer bonds with an average distance of 2.46(4) A. Two of the nitrate ligands at Er, defined by N3 and N5, are approximately trans to each other. Selected angles and distances are reported in the ESI $\dagger$ for comparison across the series. The coordination environment of the metal can be described as a spherical

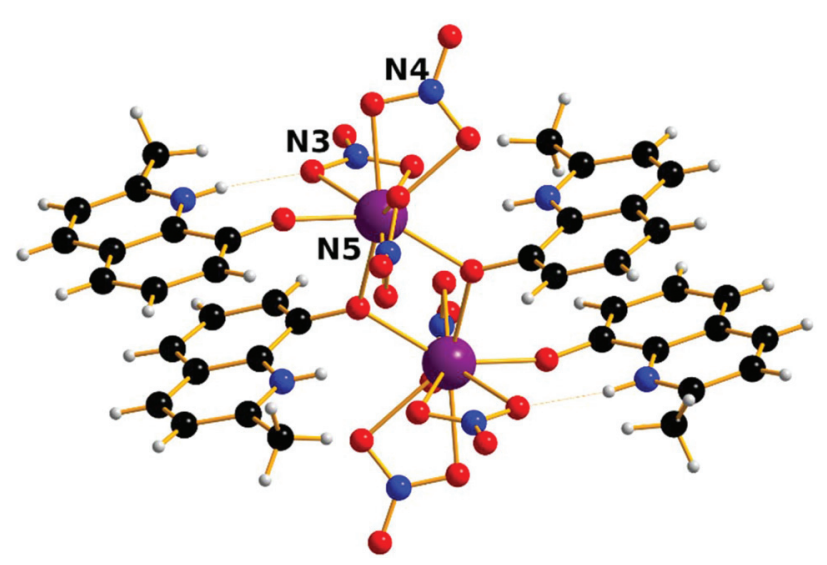

Fig. 1 Solid state molecular structure of 1; Scheme: Er, purple; N, blue; $\mathrm{O}$, red; $\mathrm{C}$, grey; $\mathrm{H}$, light grey. capped square antiprism, Fig. $\mathrm{S} 2, \dagger$ and is confirmed by the program SHAPE, Table S3. $\uparrow^{32,33}$ Despite the coordination environment being well-distributed on a sphere (i.e. arrangement of donor atoms lacking significant anisotropy), the presence of a short terminal bond to monodentate $\mathrm{HMeQ}^{*}$ will contribute to the magnetic anisotropy, as was previously found for the $\mathrm{Dy}^{\mathrm{III}}$ analogue, which behaves as a single-molecule magnet. $^{29}$

\section{Magnetometry}

The solid-state magnetic properties of $\mathbf{1}$ and $\mathbf{2}$ were studied with magnetic susceptibility measurements between 1.8-300 K. For both samples the values of $\chi_{\mathrm{M}} T$ at room temperature are close to the expected value for two non-interacting $\mathrm{Ln}^{\mathrm{III}}$ ions (Table S4 ${ }^{\dagger}$ ) and decline smoothly on cooling due to depopulation of the crystal field levels, Fig. S3.† Magnetisation data do not reveal any additional information with the $\mathrm{Yb}^{\mathrm{III}}$ analogue approaching saturation at 3.8 $\mathrm{N}_{\mathrm{A}} \mu_{\mathrm{B}}$ at $7 \mathrm{~T}$ and $2 \mathrm{~K}$, while the $\mathrm{Er}^{\mathrm{III}}$ system does not saturate reaching $10.1 \mathrm{~N}_{\mathrm{A}} \mu_{\mathrm{B}}$ at $7 \mathrm{~T}$ and $2 \mathrm{~K}$, Fig. S4. $\dagger$

\section{Investigation of $\left[\mathrm{Er}_{2}\left(\mathrm{HMeQ}^{*}\right)_{2}\left(\mathrm{NO}_{3}\right)_{6}\right](1)$}

EPR spectroscopy of magnetically dilute 1a. EPR spectroscopy was performed on magnetically diluted samples in order to establish the exchange-free properties of the $\mathrm{Ln}^{\mathrm{III}}$ ions experimentally. The dilute system 1a was measured at Q-band frequency, which revealed three rhombic $g$-values for the isolated $\mathrm{Er}^{\mathrm{III}}$ site, Fig. 2. Using the PHI software, ${ }^{34}$ these values are fitted using eqn (1) to give $g_{1}=10.72, g_{2}=4.85$ and $g_{3}=$ 2.68 , where we omit the hyperfine coupling term as no hyperfine structure is observed.

$$
\hat{H}=\mu_{\mathrm{B}} \vec{B} \cdot\left(\overline{\bar{g}}_{1} \cdot \hat{S}_{1}+\overline{\bar{g}}_{2} \cdot \hat{S}_{2}\right)+\sum_{i=1,2} \sum_{n \text { nuclei }} A_{n} \overline{\bar{I}} \cdot \hat{S}_{i}
$$

CASSCF-SO calculations of 1. Complete active space self-consistent field spin-orbit (CASSCF-SO) calculations were employed as a means of determining the principal axes for the reference

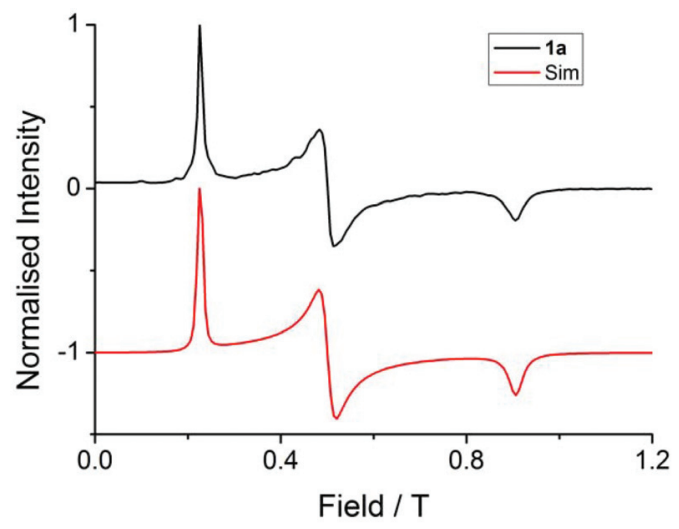

Fig. 2 Q-Band EPR measurement at $33.995818 \mathrm{GHz}$ collected at $5 \mathrm{~K}$ on the $5 \%$ diluted 1a $\left[\mathrm{Y}\{5 \% \mathrm{Er}\}_{2}(\mathrm{HMeQ})_{2}\left(\mathrm{NO}_{3}\right)_{6}\right]$ (black) with the fitted spectrum (red), following the procedure outlined in previous work. ${ }^{27}$ $g$-Values are in Table 1, linewidths: $\mathrm{lw}_{1}=1.7, \mathrm{lw}_{2}=2.3$ and $\mathrm{lw}_{3}=1.3$ $\mathrm{GHz}$. 
frame in which the $g$-matrix is diagonal and for validation of the experimentally determined $g$-values, Tables S5 and S6. $\uparrow$ Since the system is symmetric, calculations were performed on a single Ln site, where the inactive $\mathrm{Ln}^{\mathrm{III}}$ was substituted with $\mathrm{Lu}^{\mathrm{III}}$. The calculations for $\mathrm{Er}^{\mathrm{III}}$ yield theoretical $g$-values of $g_{1}=12.8, g_{2}=3.19$ and $g_{3}=1.90$ (Table S5 $\dagger$ ), which are in fair agreement with EPR data for 1a; note that there may be some change in the $g$-values associated with doping $\mathrm{Er}^{\mathrm{III}}$ into the host lattice of $3 .^{27}$ The axis associated with $g_{1}$ is oriented roughly towards the trans-nitrate ligands, while the $g_{3}$ axis is found to point towards one of the bridging $\mathrm{O} 1$ atoms, Fig. 4. The angle between the $g_{1}$-axis and the Er-Er vector is $99.0^{\circ}$, where the $g_{1}$-axis is approximately normal to the plane of the $\operatorname{Er}_{2} \mathrm{O}_{2}$ core. The first excited Kramers doublet is predicted to lie at $29 \mathrm{~cm}^{-1}$, which should not be appreciably populated at the temperature of the EPR experiment $(5 \mathrm{~K})$. The experiment is therefore interpreted assuming it has probed only the ground doublet.

EPR spectroscopy of 1 and simulation of exchange. EPR measurements of the pure dimer 1 were performed at S-, X-, Kand Q-band (Fig. 3), as the different frequencies provide comp- lementary information. The spectra at Q- and K-band frequencies show splitting of each $g$-feature into three peaks, however at lower $\mathrm{X}$ - and S-band frequencies, there are fewer discernible features and much broader peaks. As a starting point, we calculate the exact point-dipole exchange matrix (eqn (S7) †) using eqn (2) for $\mathbf{1},{ }^{28}$ and use this to simulate the coupled spectra with eqn (3) in PHI. To simulate these spectra we used the approach outlined in our previous work: ${ }^{27}$ we employ the pseudospin $S=1 / 2$ formalism where $\hat{S}_{1}$ and $\hat{S}_{2}$ are the pseudospin operators representing the ground Kramers doublets on each $\mathrm{Ln}$ ion and we define the principal $g$-values of the ground Kramers doublet on each $\mathrm{Er}^{\mathrm{III}}$ ion from those experimentally determined for $\mathbf{1 a}$, while the associated orientations of the $g$-frames with respect to the molecular geometry are taken from CASSCF-SO calculations (Fig. 4).

$$
\begin{gathered}
\overline{\bar{D}}_{\mathrm{AB}}=\frac{\mu_{\mathrm{B}}{ }^{2}}{-2 r^{2}}\left(\overline{\bar{g}}_{\mathrm{A}} \cdot \overline{\bar{g}}_{\mathrm{B}}-3\left(\overline{\bar{g}}_{\mathrm{A}} \cdot \vec{R}\right)\left(\vec{R}^{\mathrm{T}} \cdot \overline{\bar{g}}_{\mathrm{AB}}\right)\right) \\
\hat{H}=-2 \hat{S}_{1} \cdot \overline{\bar{J}} \cdot \hat{S}_{2}+\mu_{\mathrm{B}}\left(\hat{S}_{1} \cdot \overline{\bar{g}}_{1}+\hat{S}_{2} \cdot \overline{\bar{g}}_{2}\right) \cdot \vec{B}
\end{gathered}
$$
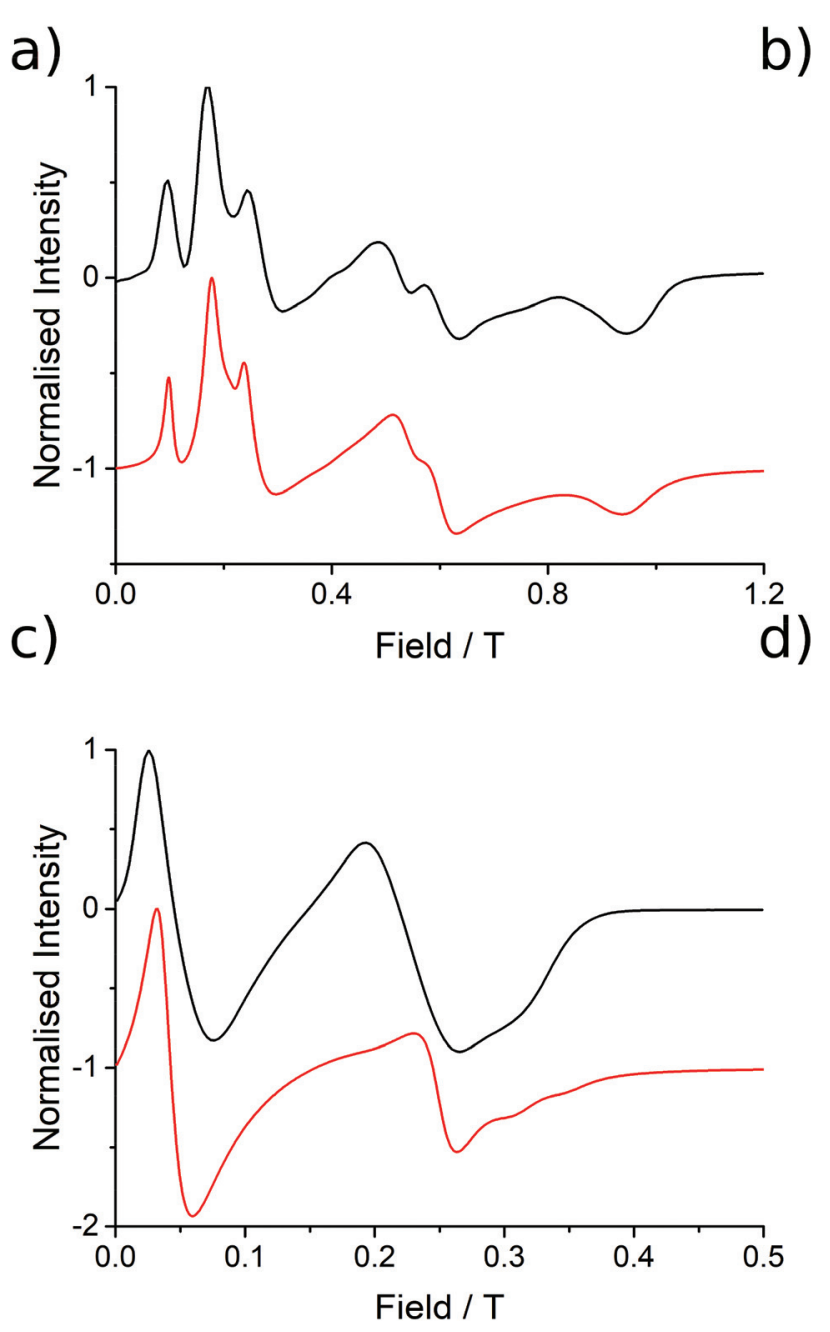
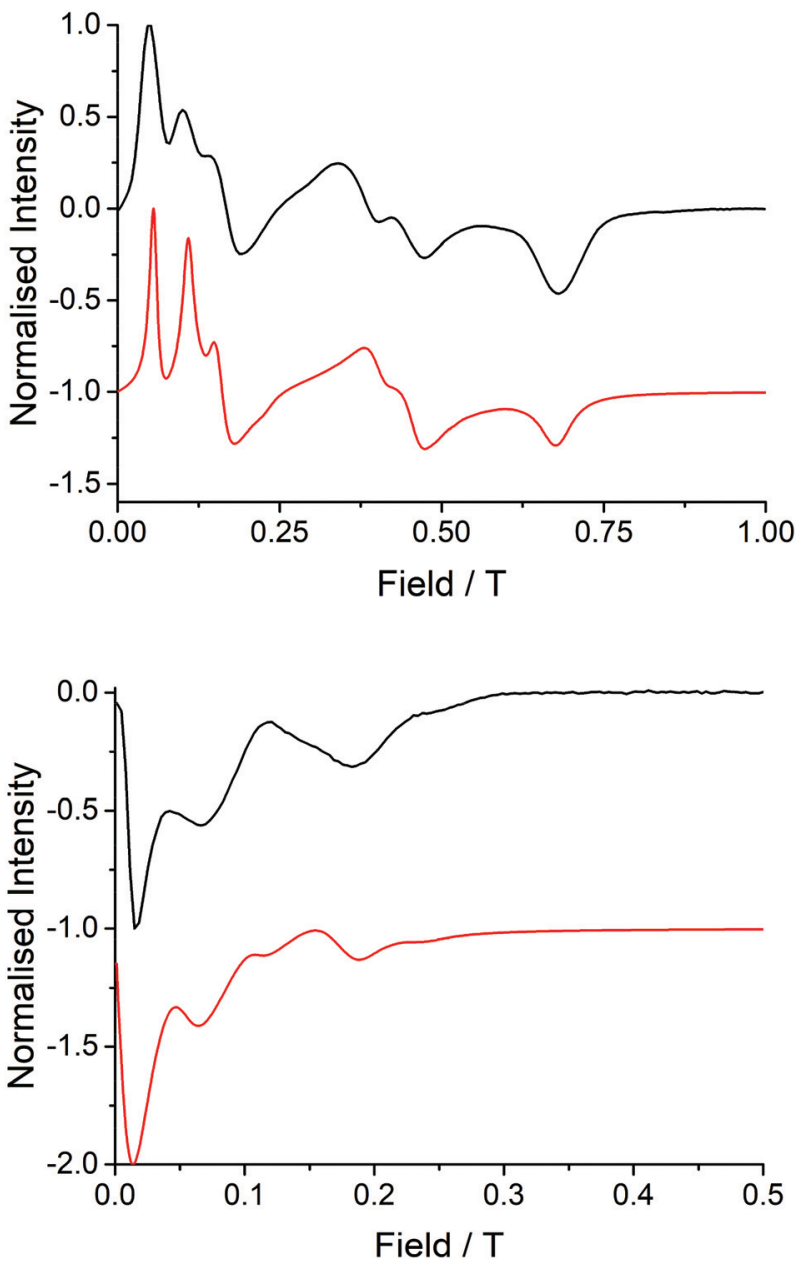

Fig. 3 EPR spectra (black lines) collected at $5 \mathrm{~K}$ for 1 at (a) Q-band (33.970818 GHz), (b) K-band (23.791 GHz), (c) X-band (9.37198 GHz) and (d) $\mathrm{S}-$ band $(3.87285 \mathrm{GHz})$, with simulations in red from the parameters presented in Table 1. 


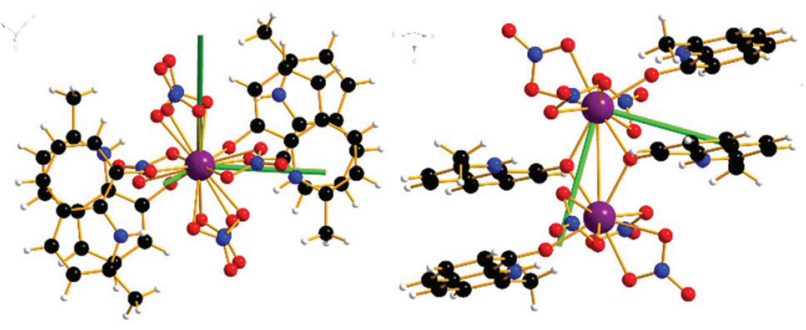

Fig. 4 Orientation of the principal $g$-axes $\left(g_{1}=\right.$ dark green) for the ground doublet from CASSCF-SO single site calculations of 1, with view down $\mathrm{Er}-\mathrm{Er}$ bond (left) and down $g_{1}$ axis (right).

These simulations (Fig. S5†) clearly show that dipolar coupling alone is not sufficient to explain the exchange interactions in $\mathbf{1}$, and hence there must be a non-zero superexchange component. Thus, following our previous work, we fit the data of the pure species with an explicit exchange coupling Hamiltonian. In this case the principal $g$-values for the two $\mathrm{Er}^{\mathrm{III}}$ ions are identical and their orientations are rigorously coparallel (due to the centre of symmetry), and we define the diagonal anisotropic exchange matrix such that the $J_{z}$ component lies along the Er-Er vector. Note that here we perform simulations in the $g$-matrix reference frame where the principal $g$-values are associated with the Cartesian axes, and due to the centre of symmetry, the only rotations required to define the orientation of the principal $g$-values with respect to the molecular geometry are the $\alpha$ and $\beta$ angles that fix $J_{z}$ along the Er-Er vector. The orientation of the $J_{x}$ and $J_{y}$ directions are left as a fitting parameter via the angle $\gamma$ (Fig. S21; $\uparrow$ corresponding to clockwise rotation around $J_{z}$ ); when $\gamma=0$, the angle between $J_{y}$ and the terminal Er-hq oxide is $c a .8^{\circ}$ (eqn (S1)-(S3) and Fig. S15 $\dagger$ ). As a result of the centre of symmetry, neither the Zeeman term (magnetic field) nor the anisotropic exchange coupling can mix the $S_{\text {eff }}=0$ and $S_{\text {eff }}=1$ states, and due to the $\Delta S=0$ and $\Delta m_{\mathrm{s}}= \pm 1$ EPR selection rules, the spectra are insensitive to the isotropic component of the exchange interaction. Therefore, we enforce a traceless exchange matrix for the modelling of 1 and 2. Surveying values of the anisotropic exchange parameters in the range $-1<J_{\mathrm{a}}<+1 \mathrm{~cm}^{-1}$ allows us to find parameters that give excellent simulations of the experimental data (Fig. 3 and Table 1). The exchange frame is shown in Fig. S15, $\uparrow$ depicting the initial and the final fitted orientations.

We present the simulation using the traceless anisotropic interaction matrix $\overline{\bar{J}}$, Fig. 3 and Table 1, which are in excellent agreement across all frequencies. A similar quality simulation, with slight variations in the peak intensities, is obtained using the opposite sign $(-\overline{\bar{J}})$ interaction matrix, Fig. S6. $\dagger$ As the reported best-fit parameters are independent of the isotropic part, there is an infinite number of solutions of the form $\pm \overline{\overline{\boldsymbol{J}}}+n \overline{\overline{\boldsymbol{I}}}$, where $n$ is any real number and $\overline{\overline{\boldsymbol{I}}}$ is the identity matrix. To estimate the isotropic component, we simulate the low temperature magnetic data using our exchange models $(+\overline{\bar{J}}$ or $-\overline{\bar{J}})$ from EPR simulations along with a variable $n$, where we find good agreement for $n$ between -0.5 and
Table 1 Simulation parameters for the fitting of EPR data for 1

\begin{tabular}{|c|c|c|c|}
\hline \multirow[t]{2}{*}{ Parameter } & \multicolumn{3}{|l|}{ Value(s) } \\
\hline & $J_{x}\left(\mathrm{~cm}^{-1}\right)$ & $J_{y}\left(\mathrm{~cm}^{-1}\right)$ & $J_{z}\left(\mathrm{~cm}^{-1}\right)$ \\
\hline$\overline{\bar{J}}$ & 0.31 & -0.25 & -0.07 \\
\hline & $g_{1}$ & $g_{2}$ & $g_{3}$ \\
\hline$\overline{\bar{g}}$ & 10.72 (fixed) & 4.85 (fixed) & 2.68 (fixed) \\
\hline & $\alpha\left({ }^{\circ}\right)$ & $\beta\left(^{\circ}\right)$ & $\gamma\left({ }^{\circ}\right)$ \\
\hline$\overline{\bar{R}}^{a}$ & 16.7 (fixed) & 261.0 (fixed) & 35.0 \\
\hline Linewidths (Lorentzian) & $\operatorname{lw}_{x}(\mathrm{GHz})$ & $\mathrm{lw}_{y}(\mathrm{GHz})$ & $\operatorname{lw}_{z}(\mathrm{GHz})$ \\
\hline Q-band & 4.0 & 5.0 & 5.0 \\
\hline K-band & 2.0 & 4.0 & 3.0 \\
\hline $\mathrm{X}$-band & 2.0 & 2.0 & 3.5 \\
\hline S-band & 2.0 & 2.0 & 3.0 \\
\hline
\end{tabular}

$+1.0 \mathrm{~cm}^{-1}$ (Fig. S12†). It is worth noting that both $+\overline{\bar{J}}$ and $-\overline{\bar{J}}$ predict lower values for magnetic data at low temperature compared with experiment, which likely indicates a positive isotropic component is needed. Despite the excellent reproduction of the experimental EPR spectra, literature has shown that while CASSCF-SO calculations are a powerful tool for approximating the electronic structure of Ln(III)-based molecules, ${ }^{35}$ the principal magnetic axes of highly-anisotropic ions are not always predicted accurately enough compared to experiment. While there tends to be good agreement for Dy(III) complexes, ${ }^{36-41}$ a landmark study found that the calculated axes for isostructural $\operatorname{Er}(\mathrm{III})$ and $\mathrm{Yb}$ (III) molecules can have significant deviations compared to experimental axes from single-crystal measurements, ${ }^{42}$ although there are counterexamples where theory is supported by experiment for $\operatorname{Er}(\mathrm{III}) .{ }^{43}$ However, due to the lack of single-crystal magnetometry/EPR data here, it is necessary to assess the validity of fixing the orientations of the principal $g$-values from CASSCF-SO calculations. Therefore, we have altered the rotation of the exchange matrix $\alpha$ and $\beta$ angles (see above) for combinations of $\pm 5^{\circ}$ and $\pm 10^{\circ}$, and re-optimised the exchange coupling parameters; here we are relying on the highly-featured nature of the multifrequency EPR spectra to validate our orientation model. Variations of $\pm 5^{\circ}$ show no visual changes to the best-fit spectra and there is no change to the fitted exchange couplings (Table S10 and Fig. S18 $\dagger$ ); at \pm 10 degrees the fits are less good in all cases, but the refined parameters are nearly identical across all fits (Table S10 and Fig. S17†). Therefore, we believe that the CASSCF-SO-calculated orientations are reliable for the purposes of extracting information on the low-lying exchange coupling.

\section{Investigation of $\left[\mathrm{Yb}_{2}\left(\mathrm{HMeQ}^{*}\right)_{2}\left(\mathrm{NO}_{3}\right)_{6}\right](2)$}

EPR spectroscopy of magnetically dilute $2 \mathrm{a}$. The $\mathrm{Yb}$ analogue was investigated in the same way, however, a 5\% dilution still gave signal from the dimetallic species, so a $2 \%$ dilution was necessary to isolate a single site. Despite the weak signal from this sample, clear $g_{1}$ and $g_{2}$ features are observed in Q-band measurements, Fig. S7. $\dagger$ These data can be fitted with Easyspin $^{44}$ to yield principal $g$-values of $g_{1}=6.15$ and $g_{2}=1.82$ 
with $g_{3}$ unobserved (hyperfine coupling constants are calculated from the linear relation between $g$ and $A,{ }^{45}$ for ${ }^{171} \mathrm{Yb} A_{i}=$ $796 g_{i}-43 \mathrm{MHz}$ and ${ }^{173} \mathrm{Yb} A_{i}=232 g_{i}-18 \mathrm{MHz}$, giving $A_{1}=4852$ and $1409 \mathrm{MHz}$ and $A_{2}=1406$ and $404 \mathrm{MHz}$, for ${ }^{171} \mathrm{Yb}$ and ${ }^{173} \mathrm{Yb}$ respectively).

CASSCF-SO calculations of 2. CASSCF-SO calculations for 2 are in reasonable agreement with the experimental data, giving $g_{1}=7.34$ and $g_{2}=1.17$, and suggest that $g_{3}=0.68$, Table $\mathrm{S} 5 ; \dagger$ this feature is out of the field range of our Q- and $\mathrm{K}$-band spectrometers, and due to the high dilution and low signal-to-noise ratio is not observable at X- and S-bands; for this CASSCF-SO-calculated $g$-value, $A_{3}$ is calculated to be $A_{3}=$ 498 and $140 \mathrm{MHz}$ for ${ }^{171} \mathrm{Yb}$ and ${ }^{173} \mathrm{Yb}$, respectively. In this case the first excited doublet lies at $223 \mathrm{~cm}^{-1}$. Similar to 1 , the $g_{1}$ principal axis points roughly between the two trans-nitrate ligands (and thus approximately normal to the $\mathrm{Yb}_{2} \mathrm{O}_{2}$ plane), while the directions of $g_{2}$ and $g_{3}$ are close to the $\mathrm{Yb}_{2} \mathrm{O}_{2}$ plane and have almost $45^{\circ}$ angles with the $\mathrm{Yb}-\mathrm{Yb}$ vector $\left(44.0^{\circ}\left(g_{2}\right)\right.$ and $\left.46.5^{\circ}\left(g_{3}\right)\right)$, Fig. 5 . In this case, the angle between the $g_{1}$ direction and the $\mathrm{Yb}-\mathrm{Yb}$ vector is $84.3^{\circ}$. The similar orientations for $\mathrm{Er}^{\mathrm{III}}$ and $\mathrm{Yb}^{\mathrm{III}}$ arise due to the similarities in the aspherical 4 f electron density distributions of the $m_{\mathrm{J}}$ states for these two ions. ${ }^{46}$

EPR spectroscopy of 2 and simulation of exchange. For 2, the EPR spectra indicate only very small interactions between the two $\mathrm{Yb}^{\mathrm{III}}$ ions due to its similar form to the EPR spectrum of 2 a, Fig. 6 and S8. $\dagger$ In 2 a, only two $g$-values could be seen at Q-band, and measurements at lower frequencies could not be obtained due to the weak signal from the $2 \%$ dilution. In the spectra of 2, the two observed $g$-values in $2 \mathrm{a}$ at Q-band are now split into doublets and there is an additional doublet in the region of the 'unobserved' high-field $g$-value at X- and S-band. The high-field feature shows a slight variation in effective $g$-values of 0.72 and 0.58 at X- and S-band, respectively, Fig. 6 (based on the mean field position of the two peaks). Here, a point-dipole calculation (eqn (2)) seems to overestimate the coupling compared to what is observed experimentally, Fig. S9 and eqn (S8), $\dagger$ suggesting that there is a small superexchange component in opposition to the dipolar coupling.

As before, the experimental $g$-values from $2 \mathbf{a}$ are used as the starting point for the model, with CASSCF-SO defining the orientation of the $g$-frames and the diagonal exchange matrix

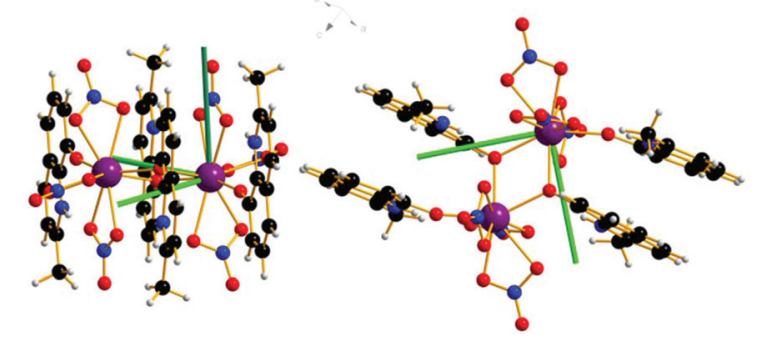

Fig. 5 Orientation of the principal g-axes $\left(g_{1}=\right.$ dark green) for the ground doublet from CASSCF-SO calculations of 2, with view perpendicular to $\mathrm{Yb}-\mathrm{Yb}$ bond (left) and down the $g_{1}$ axis (right). defined with $J_{z}$ along the interatomic $\mathrm{Yb}-\mathrm{Yb}$ vector. Comparing the spectra of $\mathbf{2}$ and $\mathbf{2 a}$, there is a clear shift in the position of the $g_{1}$ feature, which is centred at a lower field in the pure $\mathrm{Yb}_{2}$ sample, Fig. S8. $\dagger$ This observation is consistent with our previous work showing that doping into diamagnetic lattices can give slight changes in the local CF environment compared to the pure sample, which manifests as shifts in the $g$-values. ${ }^{27}$ We therefore allowed $g_{1}$ as a variable parameter in the modelling process, which gives $g_{1}=6.4$, Table 2. As the CASSCF-SO calculated $g_{3}$ value $(0.68)$ lies between the mean observed $g_{3}$ features $(0.72$ and 0.58$)$, it is fixed for the simulations. Simulating the spectra with Easyspin ${ }^{44}$ using eqn (4), we obtain good agreement with the observed spectra using an axially-symmetric exchange Hamiltonian, Fig. 6 and Table 2. As with the analysis of $\mathbf{1}$, the trace of the exchange matrix is fixed to zero. As axial symmetry is adequate for the simulation (where $J_{x}=J_{y}$ ) rotation of the exchange reference frame around $J_{z}$ is irrelevant and $\gamma$ is arbitrary. Again, the isotropic component does not influence the EPR spectrum, and inverting the sign of the reported exchange matrix $(-\overline{\bar{J}})$ gives a similar splitting with opposite relative intensities of the $g_{1}$ peaks evident in the Q- and K-band simulations, Fig. S10. $\dagger$ Here, both $+\overline{\bar{J}}$ and $-\overline{\bar{J}}$ are in good agreement with low temperature magnetic data, Fig. S13. $\dagger$ Using the magnetic data as a probe of the isotropic component, in the form $\pm \overline{\bar{J}}+n \overline{\overline{\boldsymbol{I}}}$, we find $n$ in the range -0.5 to $+0.5 \mathrm{~cm}^{-1}$, Fig. $\mathrm{S} 14 . \dagger$

To assess the accuracy of the CASSCF-SO-calculated $g$-matrix orientations, we have again altered the rotation of the exchange matrix $\alpha$ and $\beta$ angles for combinations of $\pm 5^{\circ}$ and $\pm 10^{\circ}$, and re-optimised the exchange coupling parameter. Two out of four variations of $\pm 5^{\circ}$ show good best-fit spectra while the other two are poor, but in all cases the fitted exchange coupling parameter changes by $<8 \%$ (Fig. S19 and Table S10 $\dagger$ ) At \pm 10 degrees the fits are significantly worse in all cases, but even here the exchange coupling only changes $<26 \%$ (Fig. S20 and Table S10†). Thus we believe the CASSCF-SO-calculated orientations are reliable.

$$
\hat{H}=-2 \hat{S}_{1} \cdot \overline{\bar{J}} \cdot \hat{S}_{2}+\mu_{\mathrm{B}} \vec{B} \cdot\left(\overline{\bar{g}}_{1} \cdot \hat{S}_{1}+\overline{\bar{g}}_{2} \cdot \hat{S}_{2}\right)+\sum_{i=1,2} \sum_{n} \hat{I}_{n} \cdot \overline{\bar{A}} \cdot \hat{S}_{i}
$$

\section{Discussion}

With these simulations in hand, we can compare the fitted exchange matrices to the point-dipolar ones. It is worth comparing both the magnitude of the overall exchange $\pm \overline{\overline{\boldsymbol{J}}}+n \overline{\overline{\boldsymbol{I}}}$, as well as the observed anisotropy between the largest and smallest parameters. We find that the point dipole matrix for 1 predicts only a single significant term as a result of the large coparallel principal $g_{1}$ values (eqn (S7), $\dagger$ left). Representing this dipolar interaction in the same reference frame as the final simulation (eqn (S7), $\uparrow$ right) shows major negative contributions $\left(-0.15\right.$ to $\left.-0.32 \mathrm{~cm}^{-1}\right)$ in the $J_{x x}, J_{x y}$ and $J_{y x}$ positions. The magnitudes of these terms are comparable with those 
a)

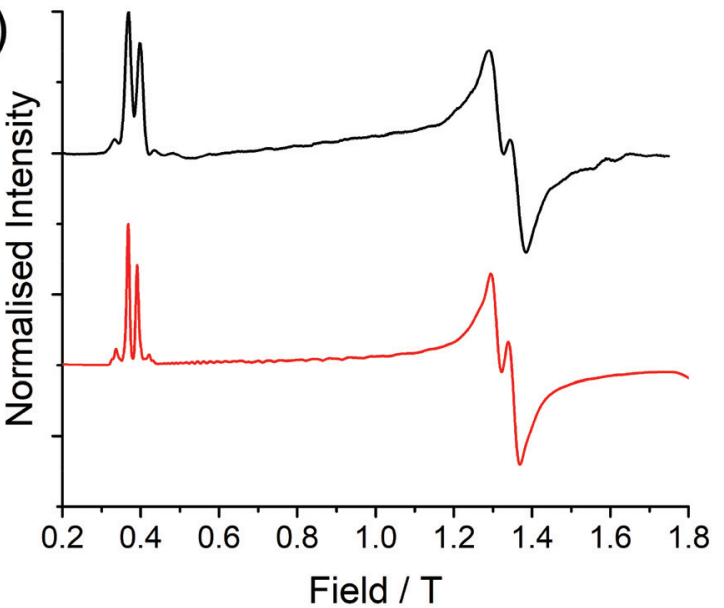

c)

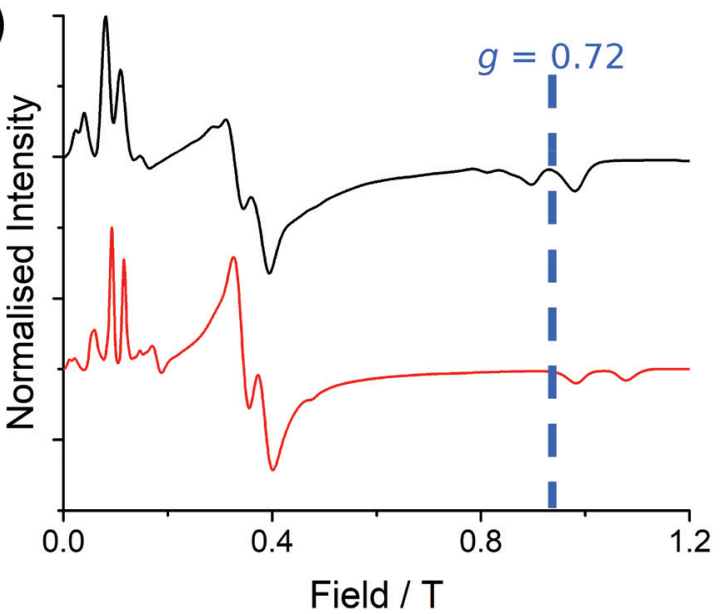

b)

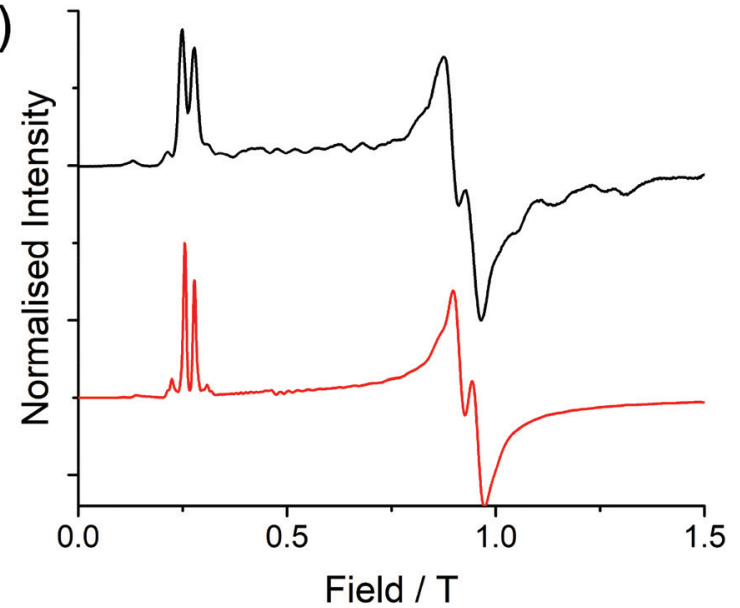

d)

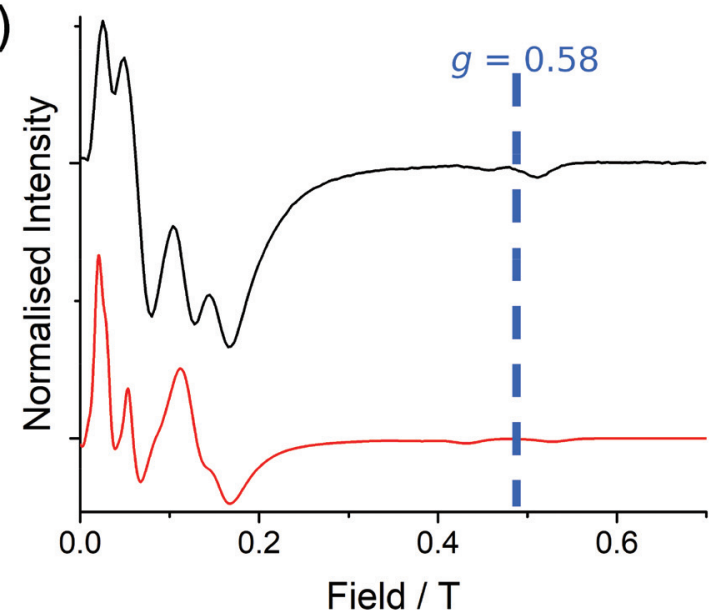

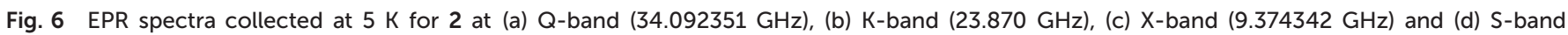

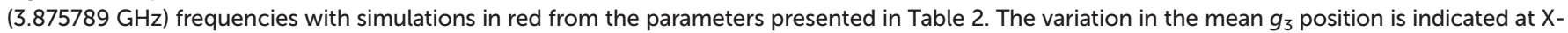
and S-band.

Table 2 Simulation parameters for the fitting of EPR data for 2

\begin{tabular}{|c|c|c|c|}
\hline Parameter & Value(s) & & \\
\hline & $J_{x}\left(\mathrm{~cm}^{-1}\right)$ & $J_{y}\left(\mathrm{~cm}^{-1}\right)$ & $J_{z}\left(\mathrm{~cm}^{-1}\right)$ \\
\hline \multirow[t]{2}{*}{$\overline{\bar{J}}$} & 0.023 & 0.023 & -0.047 \\
\hline & $A_{1}(\mathrm{MHz})$ & $A_{2}(\mathrm{MHz})$ & $A_{3}(\mathrm{MHz})$ \\
\hline$A\left({ }^{171} \mathrm{Yb}\right)$ & 5051 & 1406 & 498 \\
\hline \multirow[t]{2}{*}{$A\left({ }^{173} \mathrm{Yb}\right)$} & 1467 & 404 & 140 \\
\hline & $g_{1}$ & $g_{2}$ & $g_{3}$ \\
\hline \multirow[t]{2}{*}{$\overline{\bar{g}}$} & 6.4 & 1.8 (fixed) & 0.68 (fixed) \\
\hline & $\alpha\left({ }^{\circ}\right)$ & $\beta\left({ }^{\circ}\right)$ & $\gamma\left({ }^{\circ}\right)$ \\
\hline$\overline{\bar{R}}^{a}$ & 46.24 (fixed) & 84.26 (fixed) & 0 (fixed) \\
\hline Linewidths (FWHM) & $\operatorname{lw}_{x}$ & $\operatorname{lw}_{y}$ & $\operatorname{lw}_{z}$ \\
\hline H strain (X-, K-, Q-band) & $300 \mathrm{MHz}$ & $700 \mathrm{MHz}$ & $100 \mathrm{MHz}$ \\
\hline H strain (S-band) & $300 \mathrm{MHz}$ & $600 \mathrm{MHz}$ & $100 \mathrm{MHz}$ \\
\hline Field-space (all bands) & $8 \mathrm{mT}$ & & \\
\hline
\end{tabular}

obtained simulating the EPR spectra for $\mathbf{1}$, while the negative sign of the $J_{x x}$ component in the dipolar matrix could indicate that the true parameters are the $-\overline{\bar{J}}$ variant, Fig. S6. $\dagger$
The dipolar exchange matrix for 2 also has a single major component in the $J_{z z}$ position for the same reason as for $\mathbf{1}$. The magnitude of this term, $0.14 \mathrm{~cm}^{-1}$ (eqn (S8) $\dagger$ ), is approximately double the anisotropy in the axially-symmetric parameters required to simulate the spectrum $\left(\left|J_{\perp}-J_{\|}\right|=\right.$ $0.07 \mathrm{~cm}^{-1}$ ), explaining the overly-large splitting observed in the dipolar simulation (Fig. S9†).

The interaction of two $S_{\text {eff }}=1 / 2$ doublets results in four states arising from the coupled spin states $S_{\text {eff }}=1$ and $S_{\text {eff }}=0$, Tables S7 and S8. $\uparrow$ As discussed above with respect to EPR transitions, the energy of the $S_{\text {eff }}=0$ state is determined by the isotropic component of the interaction matrix, so has an arbitrary value in these simulations.

Exchange interactions of the magnitudes determined by the presented $\pm \overline{\overline{\boldsymbol{J}}}+n \overline{\overline{\boldsymbol{I}}}$ models are consistent with previous studies of the asymmetric dimetallic compounds $\left[\mathrm{H}_{2} \mathrm{Q}\right]\left[\mathrm{Ln}_{2}(\mathrm{Q})_{4}\left(\mathrm{NO}_{3}\right)_{3}\right] \cdot \mathrm{MeOH}$ with similar oxo bridges (on the order of $\left.c a .1 \mathrm{~cm}^{-1}\right) \cdot{ }^{27}$ In these compounds, the asymmetry allowed determination of both the isotropic and anisotropic components uniquely. 
Initially focussing on the $\left\{\mathrm{Er}_{2}\right\}$ compounds, the difference between the largest and smallest anisotropic exchange parameters is similar for $\mathbf{1}$ and $\left[\mathrm{H}_{2} \mathrm{Q}\right]\left[\mathrm{Er}_{2}(\mathrm{Q})_{4}\left(\mathrm{NO}_{3}\right)_{3}\right] \cdot \mathrm{MeOH}(0.56$ and $0.78 \mathrm{~cm}^{-1}$, respectively) and there are some similarities between the two sets of multi-frequency EPR spectra. All spectra have the major spectral feature occurring at low field, likely still having a strong relationship to the $g_{1}$ feature of the individual ions. In $\mathbf{1}$, the exchange-free $g$-features from $\mathbf{1 a}$ are still discernible as multiplet peaks, while for $\left[\mathrm{H}_{2} \mathrm{Q}\right]\left[\mathrm{Er}_{2}(\mathrm{Q})_{4}\left(\mathrm{NO}_{3}\right)_{3}\right] \cdot \mathrm{MeOH}$ it is impossible to assign the spectra in such a way. It is important to recall that $\left[\mathrm{H}_{2} \mathrm{Q}\right]\left[\mathrm{Er}_{2}(\mathrm{Q})_{4}\left(\mathrm{NO}_{3}\right)_{3}\right] \cdot \mathrm{MeOH}$ has six unique $g$-values corresponding to the two distinct and non-collinear $\mathrm{Er}^{\mathrm{III}}$ environments, ${ }^{27}$ and this is likely the origin of the increased complexity.

The biggest contrast is seen between 2 and $\left[\mathrm{H}_{2} \mathrm{Q}\right]\left[\mathrm{Yb}_{2}(\mathrm{Q})_{4}\left(\mathrm{NO}_{3}\right)_{3}\right] \cdot \mathrm{MeOH}$, where 2 is very weakly coupled and all features are clearly assignable to the $g$-features of the exchange-free ions; this is drastically different to the highly detailed spectra observed for $\left[\mathrm{H}_{2} \mathrm{Q}\right]\left[\mathrm{Yb}_{2}(\mathrm{Q})_{4}\left(\mathrm{NO}_{3}\right)_{3}\right] \cdot \mathrm{MeOH}$. Correspondingly, there is a large change in the difference between the largest and smallest anisotropic exchange parameters for 2 and $\left[\mathrm{H}_{2} \mathrm{Q}\right]\left[\mathrm{Yb}_{2}(\mathrm{Q})_{4}\left(\mathrm{NO}_{3}\right)_{3}\right] \cdot \mathrm{MeOH} \quad(0.07 v s$. $0.55 \mathrm{~cm}^{-1}$, respectively). We found that dipolar coupling alone was insufficient to describe the spectra for $\left[\mathrm{H}_{2} \mathrm{Q}\right]\left[\mathrm{Yb}_{2}(\mathrm{Q})_{4}\left(\mathrm{NO}_{3}\right)_{3}\right] \cdot \mathrm{MeOH}$, and for 2 the predicted dipolar coupling produces larger splitting in the spectra than what is observed experimentally, thus suggesting that there is a superexchange component working in opposition to the dipolar interaction in 2 . These differences are all consistent with the larger $\mathrm{Yb}-\mathrm{Yb}$ separation observed in $\mathbf{2}$ compared to $\left[\mathrm{H}_{2} \mathrm{Q}\right]\left[\mathrm{Yb}_{2}(\mathrm{Q})_{4}\left(\mathrm{NO}_{3}\right)_{3}\right] \cdot \mathrm{MeOH}$.

\section{Conclusions}

Multi-frequency EPR spectroscopy has been performed on magnetically dilute and pure samples of $\left[\operatorname{Ln}_{2}\left(\mathrm{HMeQ}^{*}\right)_{4}\left(\mathrm{NO}_{3}\right)_{6}\right]$ where $\operatorname{Ln}^{\mathrm{III}}=\operatorname{Er}^{\mathrm{III}}$ (1) and $\mathrm{Yb}^{\mathrm{III}}$ (2). The EPR spectra for the dilute samples show simple rhombic signals of the ground Kramers doublets, while the EPR spectra for the pure samples are highly-featured, providing direct evidence of the exchange interactions between the lowest lying doublets. By modelling the EPR spectra of pure samples of $\mathbf{1}$ and $\mathbf{2}$ using a combined experimental and theoretical approach, we have been able to effectively measure the exchange coupling. We find that dipolar coupling alone is not sufficient to explain the coupled spectra for 1, allowing us to infer a significant superexchange component. For 2, we find that dipolar exchange coupling is approximately twice as large as the observed exchange anisotropy, again suggesting an important, yet small, superexchange component. Compared to the asymmetric relatives of 1 and 2, $\left[\mathrm{H}_{2} \mathrm{Q}\right]\left[\mathrm{Ln}_{2}(\mathrm{Q})_{4}\left(\mathrm{NO}_{3}\right)_{3}\right] \cdot \mathrm{MeOH} \mathrm{Ln}^{\mathrm{III}}=\mathrm{Dy}^{\mathrm{III}}, \mathrm{Er}^{\mathrm{III}}$ and $\mathrm{Yb}^{\mathrm{III}}$ that we have studied previously, ${ }^{27,28}$ the magnitude of the anisotropic exchange is comparable for the $\left\{\mathrm{Er}_{2}\right\}$ dimetallics, while the symmetric $\left\{\mathrm{Yb}_{2}\right\}$ species 2 exhibits far weaker exchange coupling than $\left[\mathrm{H}_{2} \mathrm{Q}\right]\left[\mathrm{Yb}_{2}(\mathrm{Q})_{4}\left(\mathrm{NO}_{3}\right)_{3}\right] \cdot \mathrm{MeOH}$, leading to much simpler EPR spectra.

\section{Experimental section}

\section{Reagents and general procedures}

All metal salts, pro-ligands and solvent were used without further purification. Lanthanides salts $\mathrm{Ln}\left(\mathrm{NO}_{3}\right)_{3} \cdot x \mathrm{H}_{2} \mathrm{O}$, where $\mathrm{Ln}=\mathrm{Er}, \mathrm{Yb}$ and $\mathrm{Y}$ and 2-methyl-8-hydroxyquinoline were purchased from Sigma Aldrich.

\section{Infrared spectroscopy, SQUID and elemental analysis}

IR spectra of pure powders were recorded using a Thermo Scientific Nicolet iS5 IR Spectrometer equipped with an iD5 ATR. All magnetic measurements were performed using a Quantum Design MPMS-XL7 SQUID magnetometer equipped with a $7 \mathrm{~T}$ magnet. Elemental analysis of the complexes was obtained by The University of Manchester microanalytical service.

\section{X-ray crystallography}

The crystal data for compound $\mathbf{1}$ were collected on an Agilent Technologies SuperNova 4-circle diffractometer with a MoKo microfocus source and an EOS CCD detector at a temperature of $150 \mathrm{~K}$. The crystal data for compounds 2 and 3 were collected on a Bruker X8 Prospector 3-circle diffractometer with a $\mathrm{CuK} \alpha$ mircofocus source and an APEX II detector at a temperature of $100 \mathrm{~K}$.

Structure solution and refinement was performed with the Shelx package ${ }^{47}$ using the program Olex $2 .^{48}$

The structures were solved by direct methods and completed by iterative cycles full-matrix least-squares refinement against $\mathrm{F}^{2}$. All nonhydrogen atoms were refined anisotropically. Hydrogen atoms were calculated geometrically and refined in riding mode on their respective atoms.

\section{Synthesis}

The general procedure requires $1 \mathrm{mmol}$ of 2-methyl-8-hydroxyquinoline (HMeQ) added to a solution of $\operatorname{Ln}\left(\mathrm{NO}_{3}\right)_{3} \cdot x \mathrm{H}_{2} \mathrm{O}$ $(0.5 \mathrm{mmol})$ in methanol $(20 \mathrm{~mL})$, where $\mathrm{Ln}=\mathrm{Er}, \mathrm{Yb}$ and Y. Then the resultant solution was heated to reflux for 3 hours. $^{29}$ The solution was filtered and left for slow evaporation for 1 to 3 days, resulting in yellow block-shaped crystals suitable for X-ray crystallography.

The doped samples (Ln@ $\left(\mathrm{Y}_{2}\right)$ where $\operatorname{Ln}=\operatorname{Er}^{\mathrm{III}}(\mathbf{1 a}), \mathrm{Yb}^{\mathrm{III}}(\mathbf{2 a})$ were prepared by mixing $\mathrm{Ln}\left(\mathrm{NO}_{3}\right)_{3} \cdot n \mathrm{H}_{2} \mathrm{O}$ and $\mathrm{Y}\left(\mathrm{NO}_{3}\right)_{3} \cdot n \mathrm{H}_{2} \mathrm{O}$ in a 5 : 95 or $2: 98$ molar ratio with $\mathrm{HMeQ}$ in methanol according to the synthesis method above.

$\left[\operatorname{Er}_{2}\left(\mathbf{H M e Q}^{*}\right)_{2}\left(\mathbf{N O}_{3}\right)_{6}\right]$ (1). Quantities: HMeQ (0.159 g, $0.221 \mathrm{mmol}), \operatorname{Er}\left(\mathrm{NO}_{3}\right) \cdot 5 \mathrm{H}_{2} \mathrm{O}(0.221 \mathrm{~g}, 0.5 \mathrm{mmol})$. Yield $0.137 \mathrm{~g}$ (62\% based on Er). IR $\mathrm{cm}^{-1}$ : 3283(w), 3196(w), 1631(m), 1582(s), 1538(w), 1464(s), 1391(w), 1095(m), 1034(s), 893(m), 823(s), 739(s), 578(s). Elem. Anal. Calc. (\%) for $\mathrm{C}_{40} \mathrm{H}_{36} \mathrm{Er}_{2} \mathrm{~N}_{10} \mathrm{O}_{22}\left(M_{\mathrm{w}}=1340.06\right): \mathrm{C}, 35.76 ; \mathrm{H}, 2.70 ; \mathrm{N}, 10.42$; Er, 24.40; found: C, 35.40; H, 2.85; N, 10.46; Er, 23.88. 
$\left[\mathrm{Yb}_{2}\left(\mathrm{HMeQ}^{*}\right)_{2}\left(\mathrm{NO}_{3}\right)_{6}\right]$ (2). Quantities: HMeQ (0.159 g, $1 \mathrm{mmol}), \mathrm{Yb}\left(\mathrm{NO}_{3}\right) \cdot 6 \mathrm{H}_{2} \mathrm{O}(0.224 \mathrm{~g}, 1 \mathrm{mmol})$. Yield $0.134 \mathrm{~g}(60 \%$ based on $\mathrm{Yb})$. IR $\mathrm{cm}^{-1}$ : 3284(w), 3194(w), 1633(m), 1582(s), 1539(w), 1464(s), 1391(w), 1096(m), 1036(s), 894(m), 824(s), $740(\mathrm{~s}), 577(\mathrm{~s})$. Elem. Anal. Calc. (\%) for $\mathrm{C}_{40} \mathrm{H}_{36} \mathrm{Yb}_{2} \mathrm{~N}_{10} \mathrm{O}_{22}\left(M_{\mathrm{w}}\right.$ = 1356.07): C, 35.46; H, 2.67; N, 10.33; Yb, 25.54; found: $\mathrm{C}$, 35.42; H, 2.72; N, 10.41; Yb, 25.39.

$\left[\mathbf{Y}_{2}\left(\mathrm{HMeQ}^{*}\right)_{2}\left(\mathrm{NO}_{3}\right)_{6}\right]$ (3). Quantities: HMeQ $(0.159 \mathrm{~g}$, $1 \mathrm{mmol}), \mathrm{Y}\left(\mathrm{NO}_{3}\right) \cdot 6 \mathrm{H}_{2} \mathrm{O}(0.191 \mathrm{~g}, 0.5 \mathrm{mmol})$. Yield $0.106 \mathrm{~g}(56 \%$ based on Y). IR $\mathrm{cm}^{-1}$ : 3284(w), 3197(w), 1632(m), 1582(s), 1539(w), 1463(s), 1391(w), 1095(m), 1035(s), 893(m), 824(s), $740(\mathrm{~s}), 578(\mathrm{~s})$. Elem. Anal. Calc. $(\%)$ for $\mathrm{C}_{40} \mathrm{H}_{36} \mathrm{Y}_{2} \mathrm{~N}_{10} \mathrm{O}_{22}\left(M_{\mathrm{w}}=\right.$ 1186.67): C, 40.48; H, 3.05; N, 11.80; Y, 14.98; found: C, 40.52; H, 2.95; N, 11.56; Y, 14.86 .

\section{Electron paramagnetic resonance}

EPR spectra were collected at S-, X-, K- and Q-band frequencies using Bruker EMX300 and Elexsys E580 spectrometers. Measurements were performed on lightly ground polycrystalline samples restrained in eicosane as a means of avoiding magnetic torque alignment during measurements. The spectra were collected at $5 \mathrm{~K}$ cooled using either a closed cycle cooling system or liquid helium cooling.

\section{Ab initio calculations}

Complete active space self-consistent field spin-orbit (CASSCF-SO) calculations were performed using Molcas 8.0 ${ }^{49}$ on the isolated molecules using the structural solutions reported from XRD measurements. Due to the inversion symmetry of the dimetallic, only a single calculation on one of the ion sites is necessary to determine the exchange-free properties. The central ion is described using VTZP quality from the ANO-RCC library and the ion not in focus was replaced by the diamagnetic Lu ${ }^{\text {III }}$ ion. ${ }^{50,51}$ The first coordination sphere atoms use VDZP quality and all other atoms use VDZ quality. The active space comprises the $4 \mathrm{f}$ orbitals with 11 and 13 active electrons for $\mathrm{Er}^{\mathrm{III}}$ and $\mathrm{Yb}^{\mathrm{III}}$, respectively. State averaged CASSCF calculations are performed for $\mathrm{Er}^{\mathrm{III}}$ with 35 quartets and 112 doublets, with all states incorporated for SO coupling, while for $\mathrm{Yb}^{\mathrm{III}}$ only 7 doublet states are required for CASSCF and SO coupling.

\section{Conflicts of interest}

There are no conflicts to declare.

\section{Acknowledgements}

We thank The University of Manchester and EPSRC EPR National Research Facility (NS/A000055/1) for access to the EPR spectrometers and SQUID magnetometer, and the EPSRC for funding an X-ray diffractometer (grant number $\mathrm{EP}$ / K039547/1). We thank Dr Jim Raftery for assistance with X-ray crystallography. M. J. G. thanks The University of Manchester for a President's Doctoral Scholarship. S. A.-B. thanks the Higher Committee for Education Development in Iraq (HCED) for the award of a research scholarship. N. F. C. thanks The University of Manchester for a Presidential Fellowship, The Royal Society for a University Research Fellowship, and the European Research Council for a Starting Grant (ERC-2019STG-851504). R. E. P. W. thanks the EPSRC for an Established Career Fellowship (EP/R011079/1) and the European Research Council for an Advanced Grant (ERC-2017-ADG-786734). This project has received funding from the European Research Council (ERC) under the European Union's Horizon 2020 research and innovation programme (grant agreements no. 786734 and 851504).

\section{Notes and references}

1 R. J. Blagg, L. Ungur, F. Tuna, J. Speak, P. Comar, D. Collison, W. Wernsdorfer, E. J. L. McInnes, L. F. Chibotaru and R. E. P. Winpenny, Magnetic Relaxation Pathways in Lanthanide Single-Molecule Magnets, Nat. Chem., 2013, 5, 673-678.

2 K. A. Thiakou, V. Nastopoulos, A. Terzis, C. P. Raptopoulou and S. P. Perlepes, Di-2-Pyridyl Ketone in Lanthanide(III) Chemistry: Mononuclear and Dinuclear Erbium(III) Complexes, Polyhedron, 2006, 25, 539-549.

3 J. Long, F. Habib, P.-H. Lin, I. Korobkov, G. Enright, L. Ungur, W. Wernsdorfer, L. F. Chibotaru and M. Murugesu, Single-Molecule Magnet Behavior for an Antiferromagnetically Superexchange-Coupled Dinuclear Dysprosium(III) Complex, J. Am. Chem. Soc., 2011, 133, 5319-5328.

4 D. Aguilà, L. A. Barrios, V. Velasco, L. Arnedo, N. AliagaAlcalde, M. Menelaou, S. J. Teat, O. Roubeau, F. Luis and G. Aromí, Lanthanide Contraction within a Series of Asymmetric Dinuclear $\left[\mathrm{Ln}_{2}\right]$ Complexes, Chem. - Eur. J., 2013, 19, 5881-5891.

5 N. Ishikawa, M. Sugita, T. Ishikawa, S.-Y. Y. Koshihara and Y. Kaizu, Lanthanide Double-Decker Complexes Functioning as Magnets at the Single-Molecular Level, J. Am. Chem. Soc., 2003, 125, 8694-8695.

6 C. A. P. Goodwin, F. Ortu, D. Reta, N. F. Chilton and D. P. Mills, Molecular Magnetic Hysteresis at 60 Kelvin in Dysprosocenium, Nature, 2017, 548, 439-442.

7 F. Guo, B. M. Day, Y. Chen, M. Tong, A. Mansikkamäki and R. A. Layfield, Magnetic Hysteresis up to 80 Kelvin in a Dysprosium Metallocene Single-Molecule Magnet, Science, 2018, 362, 1400-1403.

8 K. S. Pedersen, A.-M. Ariciu, S. G. McAdams, H. Weihe, J. Bendix, F. Tuna and S. Piligkos, Toward Molecular $4 \mathrm{f}$ Single-Ion Magnet Qubits, J. Am. Chem. Soc., 2016, 138, 5801-5804.

9 M. Shiddiq, D. Komijani, Y. Duan, A. Gaita-Ariño, E. Coronado and S. Hill, Enhancing Coherence in Molecular Spin Qubits via Atomic Clock Transitions, Nature, 2016, 531, 348-351. 
10 P. Caravan, J. J. Ellison, T. J. McMurry and R. B. Lauffer, Gadolinium(III) Chelates as MRI Contrast Agents: Structure, Dynamics, and Applications, Chem. Rev., 1999, 99, 22932352.

11 D. Aguilà, L. A. Barrios, V. Velasco, O. Roubeau, A. Repollés, P. J. Alonso, J. Sesé, S. J. Teat, F. Luis and G. Aromí, Heterodimetallic [LnLn'] Lanthanide Complexes: Toward a Chemical Design of Two-Qubit Molecular Spin Quantum Gates, J. Am. Chem. Soc., 2014, 136, 14215-14222.

12 D. Aguilà, V. Velasco, L. A. Barrios, J. González-Fabra, C. Bo, S. J. Teat, O. Roubeau and G. Aromí, Selective Lanthanide Distribution within a Comprehensive Series of Heterometallic [LnPr] Complexes, Inorg. Chem., 2018, 57, 8429-8439.

13 J. Gónzalez-Fabra, N. A. G. Bandeira, V. Velasco, L. A. Barrios, D. Aguilà, S. J. Teat, O. Roubeau, C. Bo and G. Aromí, Thermodynamic Stability of Heterodimetallic [LnLn'] Complexes: Synthesis and DFT Studies, Chem. Eur. J., 2017, 23, 5117-5125.

14 D. Aguilà, L. A. Barrios, F. Luis, A. Repollés, O. Roubeau, S. J. Teat and G. Aromí, Synthesis and Properties of a Family of Unsymmetric Dinuclear Complexes of Ln III (Ln = Eu, Gd, Tb), Inorg. Chem., 2010, 49, 6784-6786.

15 X. Yi, G. Calvez, C. Daiguebonne, O. Guillou and K. Bernot, Rational Organization of Lanthanide-Based SMM Dimers into Three-Dimensional Networks, Inorg. Chem., 2015, 54, 5213-5219.

16 H.-B. Xu, J. Li, L.-X. Shi and Z.-N. Chen, Sensitized Luminescence in Dinuclear Lanthanide(III) Complexes of Bridging 8-Hydroxyquinoline Derivatives with Different Electronic Properties, Dalton Trans., 2011, 40, 5549.

17 R. Van Deun, P. Fias, P. Nockemann, A. Schepers, T. N. Parac-Vogt, K. Van Hecke, L. Van Meervelt and K. Binnemans, Rare-Earth Quinolinates: Infrared-Emitting Molecular Materials with a Rich Structural Chemistry, Inorg. Chem., 2004, 43, 8461-8469.

18 C. H. Chen and J. Shi, Metal Chelates as Emitting Materials for Organic Electroluminescence, Coord. Chem. Rev., 1998, 171, 161-174.

19 C. W. Tang and S. A. Vanslyke, Organic Electroluminescent Diodes, Appl. Phys. Lett., 1987, 51, 913-915.

20 M. J. Giansiracusa, S. Al-Badran, A. K. Kostopoulos, G. F. S. Whitehead, D. Collison, F. Tuna, R. E. P. Winpenny and N. F. Chilton, A Large Barrier Single-Molecule Magnet without Magnetic Memory, Dalton Trans., 2019, 48, 1079510798.

21 G. B. Deacon, C. M. Forsyth, P. C. Junk and A. Urbatsch, Syntheses at Elevated Temperature and Structures of Lanthanoid/Alkaline Earth Heterobimetallic Derivatives of 2-Methyl-8-Hydroxyquinoline, Eur. J. Inorg. Chem., 2010, 3, 2787-2797.

22 G. B. Deacon, C. M. Forsyth, O. Gazukin, P. C. Junk, G. Meyer, J. Sierau and D. R. Turner, An Unexpected Coupling Reaction of 8-Quinolinolate at Elevated Temperature, Aust. J. Chem., 2014, 67, 1251-1256.
23 G. B. Deacon, C. M. Forsyth, P. C. Junk and S. G. Leary, A Rare Earth Alloy as a Synthetic Reagent: Contrasting Homometallic Rare Earth and Heterobimetallic Outcomes, New J. Chem., 2006, 30, 592-596.

24 G. B. Deacon, P. C. Junk, S. G. Leary and A. Urbatsch, Expanding the Series of $\left[\mathrm{RE}_{2} \mathrm{Ca}(\mathrm{OQ})_{8}\right]$ Structures: New Heterobimetallic Rare Earth/Alkaline Earth 8-Quinolinolate Complexes, Z. Anorg. Allg. Chem., 2012, 638, 2001-2007.

25 S. G. Leary, G. B. Deacon and P. C. Junk, The Synthesis of a Homoleptic Lanthanoid Complex of the 8-Quinolinolate Ion Directly from the Metal, Z. Anorg. Allg. Chem., 2005, 631, 2647-2650.

26 G. B. Deacon, T. Dierkes, M. Hübner, P. C. Junk, Y. Lorenz and A. Urbatsch, Alkali Metal/Lanthanoid Heterobimetallic Complexes of 8-Hydroxyquinolines Accessed by PseudoSolid-State Reactions, Eur. J. Inorg. Chem., 2011, 4338-4348.

27 M. J. Giansiracusa, E. Moreno-Pineda, R. Hussain, R. Marx, M. Martínez Prada, P. Neugebauer, S. Al-Badran, D. Collison, F. Tuna, J. van Slageren, S. Carretta, T. Guidi, E. J. L. McInnes, R. E. P. Winpenny and N. F. Chilton, Measurement of Magnetic Exchange in Asymmetric Lanthanide Dimetallics: Toward a Transferable Theoretical Framework, J. Am. Chem. Soc., 2018, 140, 2504-2513.

28 E. Moreno Pineda, N. F. Chilton, R. Marx, M. Dörfel, D. O. Sells, P. Neugebauer, S. Jiang, D. Collison, J. van Slageren, E. J. L. McInnes and R. E. P. Winpenny, Direct Measurement of Dysprosium(III)...dysprosium(III) Interactions in a Single-Molecule Magnet, Nat. Commun., 2014, 5, 5243.

29 F. Yang, Q. Zhou, G. Zeng, G. Li, L. Gao, Z. Shi and S. Feng, Anion Effects on the Structures and Magnetic Properties of Binuclear Lanthanide Single-Molecule Magnets, Dalton Trans., 2014, 43, 1238-1245.

30 L. Mandal, S. Biswas, G. Cosquer, Y. Shen and M. Yamashita, Anion-Driven Structures and SMM Behavior of Dinuclear Terbium and Ytterbium Complexes, Dalton Trans., 2018, 47, 17493-17499.

31 P. P. Hallmen, H. J. Werner, D. Kats, S. Lenz, G. Rauhut, H. Stoll and J. Van Slageren, Toward Fast and Accurate: Ab Initio Calculation of Magnetic Exchange in Polynuclear Lanthanide Complexes, Phys. Chem. Chem. Phys., 2019, 21, 9769-9778.

32 A. Ruiz-Martínez, D. Casanova and S. Alvarez, Polyhedral Structures with an Odd Number of Vertices: NineCoordinate Metal Compounds, Chem. - Eur. J., 2008, 14, 1291-1303.

33 P. Llunell, M. Casanova, D. Cirera, J. Bofill, J. M. Alemany and D. Alvarez, S. Pinsky and M. Avnir, SHAPE 2.1, Universitat de Barcelona and The Hebrew University of Jerusalem, Barcelona and Jerusalem, 2003.

34 N. F. Chilton, R. P. Anderson, L. D. Turner, A. Soncini and K. S. Murray, PHI: A Powerful New Program for the Analysis of Anisotropic Monomeric and Exchange-Coupled Polynuclear d- and f-Block Complexes, J. Comput. Chem., 2013, 34, 1164-1175. 
$35 \mathrm{~J}$. Luzon and R. Sessoli, Lanthanides in Molecular Magnetism: So Fascinating, so Challenging, Dalton Trans., 2012, 41, 13556-13567.

36 Y. Fang, M. X. Xu, Y. C. Hui, H. L. Sun, X. Yan and S. Da Jiang, Determination of the Magnetic Principal Axes of a Dysprosium Complex with Slow Relaxation on a Single Crystal, J. Magn. Magn. Mater., 2019, 490, 165475.

37 T. T. da Cunha, J. Jung, M. E. Boulon, G. Campo, F. Pointillart, C. L. M. Pereira, B. Le Guennic, O. Cador, K. Bernot, F. Pineider, S. Golhen and L. Ouahab, Magnetic Poles Determinations and Robustness of Memory Effect upon Solubilization in a DyIII-Based Single Ion Magnet, J. Am. Chem. Soc., 2013, 135, 16332-16335.

38 K. Qian, J. J. Baldoví, S. Da Jiang, A. Gaita-Ariño, Y. Q. Zhang, J. Overgaard, B. W. Wang, E. Coronado and S. Gao, Does the Thermal Evolution of Molecular Structures Critically Affect the Magnetic Anisotropy?, Chem. Sci., 2015, 6, 4587-4593.

39 K. Bernot, J. Luzon, L. Bogani, M. Etienne, C. Sangregorio, M. Shanmugam, A. Caneschi, R. Sessoli and D. Gatteschi, Magnetic Anisotropy of Dysprosium(III) in a Low-Symmetry Environment: A Theoretical and Experimental Investigation, J. Am. Chem. Soc., 2009, 131, 5573-5579.

40 G. Cucinotta, M. Perfetti, J. Luzon, M. Etienne, P.-E. Car, A. Caneschi, G. Calvez, K. Bernot and R. Sessoli, Magnetic Anisotropy in a Dysprosium/DOTA Single-Molecule Magnet: Beyond Simple Magneto-Structural Correlations, Angew. Chem., 2012, 124, 1638-1642.

41 N. F. Chilton, D. Collison, E. J. L. McInnes, R. E. P. Winpenny and A. Soncini, An Electrostatic Model for the Determination of Magnetic Anisotropy in Dysprosium Complexes, Nat. Commun., 2013, 4, 2551.

42 M.-E. Boulon, G. Cucinotta, J. Luzon, C. Degl'Innocenti, M. Perfetti, K. Bernot, G. Calvez, A. Caneschi and R. Sessoli, Magnetic Anisotropy and Spin-Parity Effect Along the Series of Lanthanide Complexes with DOTA, Angew. Chem., Int. Ed., 2013, 52, 350-354.

43 M. Perfetti, G. Cucinotta, M. E. Boulon, F. ElHallak, S. Gao and R. Sessoli, Angular-Resolved Magnetometry beyond Triclinic Crystals Part II: Torque Magnetometry of
Cp*ErCOT Single-Molecule Magnets, Chem. - Eur. J., 2014, 20, 14051-14056.

44 S. Stoll and A. Schweiger, EasySpin, a Comprehensive Software Package for Spectral Simulation and Analysis in EPR, J. Magn. Reson., 2006, 178, 42-55.

45 R. G. Denning, J. Harmer, J. C. Green and M. Irwin, Covalency in the $4 \mathrm{f}$ Shell of Tris-Cyclopentadienyl Ytterbium $\left(\mathrm{YbCp}_{3}\right)$-A Spectroscopic Evaluation, J. Am. Chem. Soc., 2011, 133, 20644-20660.

46 J. Sievers, Asphericity of 4f-Shells in Their Hund's Rule Ground States, Z. Phys. B: Condens. Matter, 1982, 45, 289296.

47 G. M. Sheldrick, A Short History of SHELX, Acta Crystallogr., Sect. A: Found. Crystallogr., 2008, 64, 112-122.

48 O. V. Dolomanov, L. J. Bourhis, R. J. Gildea, J. A. K. Howard and H. Puschmann, OLEX2: A Complete Structure Solution, Refinement and Analysis Program, J. Appl. Crystallogr., 2009, 42, 339-341.

49 F. Aquilante, J. Autschbach, R. K. Carlson, L. F. Chibotaru, M. G. Delcey, L. De Vico, I. F. Galván, N. Ferré, L. M. Frutos, L. Gagliardi, M. Garavelli, A. Giussani, C. E. Hoyer, G. Li Manni, H. Lischka, D. Ma, P. Å. Malmqvist, T. Müller, A. Nenov, M. Olivucci, T. B. Pedersen, D. Peng, F. Plasser, B. Pritchard, M. Reiher, I. Rivalta, I. Schapiro, J. Segarra-Martí, M. Stenrup, D. G. Truhlar, L. Ungur, A. Valentini, S. Vancoillie, V. Veryazov, V. P. Vysotskiy, O. Weingart, F. Zapata and R. Lindh, Molcas 8: New Capabilities for Multiconfigurational Quantum Chemical Calculations across the Periodic Table, J. Comput. Chem., 2016, 37, 506541.

50 B. O. Roos, R. Lindh, P.-Å. Malmqvist, V. Veryazov, P.-O. Widmark and A. C. Borin, New Relativistic Atomic Natural Orbital Basis Sets for Lanthanide Atoms with Applications to the Ce Diatom and LuF3, J. Phys. Chem. A, 2008, 112, 11431-11435.

51 B. O. Roos, R. Lindh, P. Å. Malmqvist, V. Veryazov and P. O. Widmark, Main Group Atoms and Dimers Studied with a New Relativistic ANO Basis Set, J. Phys. Chem. A, 2004, 108, 2851-2858. 